ROSA, Murilo de Sousa. Incursões fantasiosas: o modernismo primitivista na arte de Willy Zumblick, 1973. Domínios da Imagem, Londrina, v. 10, n. 19, p. 189-211, jul./dez. 2016.

ISSN 2237-9126

Recebido em 13/5/2015 e aprovado em 8/7/2016

\title{
INCURSÕES FANTASIOSAS: O MODERNISMO PRIMITIVISTA NA ARTE DE WILLY ZUMBLICK, 1973
}

Murilo de Sousa Rosa'

\section{Resumo}

O artista plástico Willy Zumblick foi agraciado pela mídia catarinense, durante a segunda metade do século XX, por contemplar em suas pinturas a diversidade cultural e alguns episódios da história do seu Estado. Suas biografias tratam também dos estilos trabalhados pelo pintor; porém, oferecem poucas referências quanto às circunstâncias que influenciaram suas escolhas. Faz parte do conjunto artístico de Zumblick telas tanto do viés acadêmico quanto modernista. Entretanto, uma coleção de pouco mais de cem quadros chama a atenção por ter sido pintada em estilo modernista primitivista. Devido à escassez de informações sobre este conjunto, o artigo tem por objetivo compreender as circunstâncias que contribuíram para a produção das telas primitivistas de Willy Zumblick do ano de 1973. Esse texto foi desenvolvido com base em uma pesquisa e análise sobre as bibliografias do artista, artigos de jornais e imagens de seus quadros.

Palavras-chave: Willy Zumblick. Arte. Acadêmico. Modernista. Primitivismo.

\begin{abstract}
The plastic artist Wily Zumblick was awarded by the Santa Catarina media, during the second half of the twentieth century, to contemplate in his paintings the cultural diversity and some episodes of his State's history. His biographies also approach some styles used by the painter; but they offer a few references related to the circumstances that influenced his choices. In his artistic set, there are both academic and modernist paintings. However, a collection of about hundred paintings draws the attention because it was painted in a primitivist modernist style. Due to the scarcity of information about this set, this paper intends to understand the circumstances that contributed to the production of the primitivist paintings of Wily Zumblick in 1973. This texts was developed based on a research and analyses of the bibliography of the artist, as well newspaper articles and images of his paintings.
\end{abstract}

Keywords: Wily Zumblick. Art. Academic. Modernist. Primitivism.

\footnotetext{
1 Murilo de Sousa Rosa. Mestrando do curso de História do PPGH-UDESC e bolsista CAPES. Email: murilo2801@yahoo.com.br
} 
ROSA, Murilo de Sousa. Incursões fantasiosas: o modernismo primitivista na arte de Willy Zumblick, 1973. Domínios da Imagem, Londrina, v. 10, n. 19, p. 189-211, jul./dez. 2016.

ISSN 2237-9126

"Estilo inconfundível". É com esta expressão que a pesquisadora Lélia Pereira da Silva Nunes (1993, p. 33) definiu a arte de Willy Zumblick em sua obra, Zumblick - uma história de vida e arte, e segundo autora, as obras produzidas pelo pintor tubaronense trazem consigo uma estética que as distingue de outras produções no mundo das artes plásticas. No entanto, as linhas seguintes não esclarecem que estilo é esse que pode ser identificado em seus trabalhos. A biografia foi a primeira a apresentar, além de um resumo sobre a vida do artista, o conjunto temático desenvolvido por Willy em anos de pintura e exposições, desde o fim da década de 1930 até o início da década de 1990, incluindo aspectos da geografia, da religiosidade, do folclore, dos hábitos culturais, personagens populares, retratos e episódios da história catarinense. A autora optou em escrever uma história linear, deixando de fora a análise dos estilos de pintura já trabalhados pelo artista, bem como as circunstâncias que influenciaram suas opções estéticas. Outras biografias sobre Willy foram editadas, mas só em 2010 é que o assunto da diversidade estética de seus trabalhos foi abordado no livro Zumblick para sempre - catálogo de obras. Neste impresso, alguns estilos de pintura são apontados e descritos, mas permanece ausente uma análise que trate dos eventos que contribuíram e foram determinantes para que o artista escolhesse as formas de representar seus temas.

Ao revisar as biografias e as imagens de seus trabalhos contidas nas mesmas, é notável a diversidade estética que Willy utilizou para representar seus motivos prediletos. As imagens das obras mostram o quanto Willy foi dinâmico, tendo ele produzido tanto pelos cânones do academicismo quanto pelo modernismo.

No ano de 2013, foi comemorado por instituições catarinenses, entre elas universidades, revistas, jornais e a Assembleia Legislativa do Estado, os cem anos do nascimento do pintor, reafirmando referências 
ROSA, Murilo de Sousa. Incursões fantasiosas: o modernismo primitivista na arte de Willy Zumblick, 1973. Domínios da Imagem, Londrina, v. 10, n. 19, p. 189-211, jul./dez. 2016.

ISSN 2237-9126

consagradas atribuídas a ele, tais como o pintor das bandeiras do Divino, pintor regionalista, cronista da história, pintor folclorista e pintor memorialista. Essas dedicatórias recentes, contidas nas publicações comemorativas, são expressões que repetem a fala de diversos depoimentos de amigos e admiradores presentes em suas biografias, e que assim, muito próximo desses discursos, revitalizam muito do que já foi dito e escrito sobre este homem das artes, deixando de fora, mais uma vez, outros fatores peculiares e relevantes de seu trabalho.

É justamente essa ausência que instiga a escrita deste artigo. No entanto, por se tratar de uma ampla produção que diversificou no aspecto estético, não é possível que todas as suas características possam ser analisadas neste espaço. O motivo que estimulou esta pesquisa foram as escassas informações sobre um conjunto de telas produzidas do ano de 1973, e que recebeu do crítico de arte Antônio Minguetti a definição de pós-impressionismo primitivista. Porém, o texto de Minguetti, publicado no livro Zumblick para sempre, é breve e apenas descritivo. Devido a essa lacuna surge a seguinte questão: que fatores estimularam o artista a optar pelo primitivismo para pintar tais obras? Com base nessa reflexão este artigo tem por objetivo analisar as circunstâncias que contribuíram para a produção das telas primitivistas de Willy Zumblick do ano de 1973.

O desenvolvido deste artigo foi realizado com base em uma pesquisa sobre as biografias do artista, uma investigação em jornais pertencentes ao Arquivo Público de Tubarão, além da leitura e a análise das imagens de algumas de suas obras.

O título desse artigo, Incursões fantasiosas, é uma referência a uma ideia defendida por Zumblick, na qual todo artista deveria se "aventurar" em outras opções estéticas. Na primeira parte deste trabalho, intitulada Outras experiências estéticas, procuro identificar as 
ROSA, Murilo de Sousa. Incursões fantasiosas: o modernismo primitivista na arte de Willy Zumblick, 1973. Domínios da Imagem, Londrina, v. 10, n. 19, p. 189-211, jul./dez. 2016.

ISSN 2237-9126

influências artísticas sobre a produção modernista de Zumblick a partir da década de 1940. E por último, em Primitivista e renovador, procuro analisar quais as circunstâncias que foram determinantes para o artista produzisse, em 1973, suas telas primitivistas.

\section{Outras Experiências Estéticas}

Quando Willy Zumblick passou a desempenhar a atividade de relojoeiro junto com seu pai na década de 1930 na pequena cidade de Tubarão, no sul de Santa Catarina, dava também seus primeiros passos para produzir e expor como artista profissional. Além disso, Zumblick fazia suas primeiras escolhas quanto ao modo de representar esteticamente os motivos que os consagrariam, anos depois, através da mídia, como um dos mais destacados pintores do Estado.

Zumblick iniciou seus estudos sobre a pintura acadêmica desde muito jovem, e aprimorou sua produção no decorrer dos anos seguintes. Ainda criança, começou suas lições como aprendiz do pintor alemão Frederico Guilherme Lobe, professor da Escola Alemão de Belas Artes de Porto Alegre, e que estava de passagem por Tubarão para pintar cenas bíblicas na Igreja Nossa Senhora da Piedade. (NUNES, 1993, p. 19).

No entanto, o contato de Willy com a arte acadêmica não se limitou as lições aprendidas com Lobe. Em 1946, Willy tomou a iniciativa de expor na capital do país, o Rio de Janeiro, em uma sala da Associação Brasileira de Imprensa. Durante a mostra, a imprensa carioca dedicou notas elogiosas a seus trabalhos, e aproveitando o convite, ingressou na Sociedade Brasileira de Belas Artes como sócio correspondente, e com a oportunidade, assistiu aulas e excursionou pela cidade junto com mestres e alunos. (NUNES, 1993, p. 56).

Porém, o crítico de arte Antônio A. Minguetti (2010) chama a atenção sobre a produção artística de Willy Zumblick ao dizer que ela 
ROSA, Murilo de Sousa. Incursões fantasiosas: o modernismo primitivista na arte de Willy Zumblick, 1973. Domínios da Imagem, Londrina, v. 10, n. 19, p. 189-211, jul./dez. 2016.

ISSN 2237-9126

não seguiu apenas convenções acadêmicas. Ao tratar da diversidade de estilos em suas telas, o pintor direcionou uma crítica a arte moderna, e disse que "A modernidade na pintura nos países da Europa e, mesmo, aqui, no Brasil, veio facilitar, e muito, tanto os bons e os maus artistas", e ao questionar as pretensões dos modernistas, desabafou: "Não sei se a intenção era sepultar os pintores acadêmicos, como se esses fossem retrógrados e que não enxergavam além de seus narizes". (ZUMBLICK, 1998, p. 110).

Willy procurou afirmar que não era um artista "retrógrado", pois defendeu que "expoentes da arte de bem pintar, também fizeram incursões fantasiosas, hoje chamada de arte moderna", (ZUMBLICK, 1998, p. 110) e que ele também sabia incursionar pelas experiências estéticas.

Levando em conta essas observações, torna-se pertinente observar quais circunstâncias influenciaram Zumblick a trabalhar com outras formas estéticas em suas obras, e quais aspectos da pintura modernistas podem ser reconhecidos em suas telas. Por esse motivo, a revisão de alguns eventos que ajudaram a consolidar o modernismo no Brasil e em Santa Catarina ajuda a compreender o percurso de Zumblick nesse seguimento estético. Como observou a pesquisadora Martine Joly (2007), uma das premissas indispensáveis para a análise das mensagens visuais é o contexto de sua aparição.

Para Couto (2005), o país entrou na modernidade cultural com a formação de um grupo de intelectuais e artistas que promoveram a Semana de Arte Moderna em fevereiro de 1922, realizada no Teatro Municipal de São Paulo, e incorporando as experiências da vanguarda europeia que rompem com todos os estilos de arte realizados antes deles. A arte moderna brasileira, com o intuito de se diferenciar do academicismo na pintura e na poesia, seguiu o mesmo caminho. Em 
ROSA, Murilo de Sousa. Incursões fantasiosas: o modernismo primitivista na arte de Willy Zumblick, 1973. Domínios da Imagem, Londrina, v. 10, n. 19, p. 189-211, jul./dez. 2016.

ISSN 2237-9126

1924 o grupo passou a priorizar, além do rompimento estético vanguardista, temas da cultura popular, incluindo lendas, o folclore, festas, costumes e paisagens. Já na era Vargas a qualidade de uma obra de arte estava relacionada ao grau de nacionalismo contido nela. A partir daí a arte moderna brasileira deveria se preocupar com a mensagem, e não apenas com a criação do belo ou a expressão da subjetividade, além de desenvolver a função de integração nacional, voltada para o coletivo. Desse modo, se a princípio bastava uma estilização inovadora, com o passar dos anos o modernismo brasileiro privilegiou a comunicação e a realidade brasileira.

A experiência de Willy com a Escola Nacional de Belas Artes, provavelmente, contribuiu para que o pintor catarinense tivesse um de seus primeiros contatos com a arte moderna. Ao chegar à instituição em 1946 esta já havia passado por transformações quanto ao seu ensino, devido a uma divisão provocada pelo grupo de pintores conhecido como Núcleo Bernadelli. Constituído no início da década de 1930, o Núcleo era formado por alunos de classe menos favorecida e que se reuniam nas noites para pintar casarios, lugares públicos, paisagens e debater sobre arte. O grupo contestava o academicismo ensinado na ENBA e o Salão Nacional de Belas Artes, pois este premiava de forma hierarquizada, favorecendo jovens artistas que já haviam passado por outros salões oficiais. Em 1931 o Ministro da Educação Belizário Pena concedeu ao grupo que se instalasse nos porões da ENBA, e estudando a noite tiveram como professores Manoel Santiago, Bruno Lechovski e Quirino Campofiorito. Enquanto o arquiteto Lúcio Costa foi diretor da Escola em 1930/1 este procurou atualizar os cursos, contratando professores modernos, sendo alguns estrangeiros, mas as circunstâncias foram contestadas pelos por alguns alunos devido à valorização do nacionalismo, e Lúcio foi retirado do cargo. Assumiu 
ROSA, Murilo de Sousa. Incursões fantasiosas: o modernismo primitivista na arte de Willy Zumblick, 1973. Domínios da Imagem, Londrina, v. 10, n. 19, p. 189-211, jul./dez. 2016.

ISSN 2237-9126

então o acadêmico Arquimedes Memória, que se opôs ao Núcleo. Quando professores como Edson Motta, Bustamante Sá e Pancetti passaram a ministrar aulas para o Núcleo Bernardelli, a situação provocou desconforto e confrontos dentro da Escola. Os professores tradicionais se mobilizaram e conseguiram retirar o Núcleo dos porões da ENBA em 1935, mas devido às pressões foi criada então, em 1940, a Divisão Moderna do Salão Nacional de Belas Artes, e os modernos ganharam seu espaço. Em 1941, José Pancetti expôs sua tela, "Chão", e se tornou o primeiro moderno a conquistar o prêmio "Viagem ao Exterior". (LUZ, 2002).

Certa vez, Willy argumentou que Pancetti figurava entre os modernistas que mais admirava, (ZUMBLICK, 2010) e sendo este membro e professor do Núcleo Bernardelli, é considerável que as mudanças provocadas nos ensinos das artes plásticas na ENBA, ocorridas apenas alguns anos antes da ida de Zumblick ao Rio, também se tornaram referências marcantes para seus trabalhos. Desse modo, seu contato com a ENBA possibilitou não só ampliar seus conhecimentos sobre o academicismo, mas oportunizou o contato e a aprendizagem com outras experiências estéticas.

Os eventos da Semana de 22 não repercutiram nos periódicos da capital catarinense na época, e passaram mais de duas décadas até que a arte moderna chamasse a atenção no Estado. Em 1946, alguns moços passam a publicar no jornal Folha da Juventude de Florianópolis, e na sua quinta edição, em 1947, um deles, Anibal Nunes Pires, tratou de dirigir uma página sobre arte moderna. Em agosto deste mesmo ano criaram o Círculo de Arte Moderna, incluindo poetas, escultores, desenhistas e pintores, e em Janeiro de 1948 o grupo criou uma publicação intitulada Revista Sul. Essa formação, que também ficou conhecida Grupo Sul, falava em inovar o campo artístico contra o que 
ROSA, Murilo de Sousa. Incursões fantasiosas: o modernismo primitivista na arte de Willy Zumblick, 1973. Domínios da Imagem, Londrina, v. 10, n. 19, p. 189-211, jul./dez. 2016.

ISSN 2237-9126

eles chamavam de ambiente cultural acomodado, provinciano e academicista. O Grupo se manifestava contra esse seguimento artístico, segundo eles, por só trabalhar com a atividade da cópia, e alegavam que o modernismo era renovador por se interessar por temas sociais e pela realidade do cotidiano. No ano de 1949 criam, com o apoio do governo estadual de Aderbal Ramos da Silva, o Museu de Arte Moderna de Santa Catarina em Florianópolis, e através de sua revista deram projeção a vários artistas locais, além de possibilitar aos florianopolitanos de se familiarizarem com as artes de Portinari, Bruno Giorgi, Goeldi, Picasso, Cezanne, Carlos Scliar, entre outros. (JUNKES, 1982).

Quando o Grupo Sul anunciou seu encerramento em 1957, O Instituto Brasil-Estados Unidos inaugurou suas atividades culturais com uma exposição sobre motivos catarinenses, organizada por Hassis e Mayer Filho, ex-membros do Grupo Sul, e logo em 1958 criaram, junto com outros pintores modernistas da ilha, O GAPF - Grupo de Artistas Plásticos de Florianópolis. (SABINO, 1981, p. 73).

O GAPF foi criado com o intuito de dar continuidade ao ideal renovador para as artes plásticas da cidade. Eram inspirados nos pintores fauvistas e expressionistas, e assim como o extinto Grupo Sul, sua fala era a de valorização de temas relacionados ao cotidiano ilhéu, onde aparecem cenas de trabalho, lazer e costumes locais da vida de pessoas comuns. Com o ingresso de novos membros os temas dos trabalhos incluíam, além da gente simples da llha, suas ruas, praças, esquinas, quintais, praias e ações do cotidiano, mantendo a subjetividade do artista, a realização livre e inventiva. Com relação ao abstracionismo, este não conseguiu adeptos no GAPF, que preferiu continuar representado figurativamente, mas não de forma realista. (ANDRADE FILHO, 2001). 
ROSA, Murilo de Sousa. Incursões fantasiosas: o modernismo primitivista na arte de Willy Zumblick, 1973. Domínios da Imagem, Londrina, v. 10, n. 19, p. 189-211, jul./dez. 2016.

ISSN 2237-9126

Quando surgiram na capital catarinense os primeiros interessados pela arte moderna, Willy logo produziu duas telas abstratas no ano de 1949. Uma é intitulada Pecado Capital - Ira, e a outra Pecado Capital Soberba. A primeira tela é uma pintura a óleo sobre tela, com medidas $0,70 \mathrm{~m} \times 0,70 \mathrm{~m}$, e nela se observa formas geométricas com contornos pretos e pinceladas irregulares. Foram aplicadas grandes manchas de cor, nas quais predominam azul claro, alaranjado, e diferentes tonalidades de verde. Na segunda obra, óleo sobre tela, 0,70m $\times 0,70 \mathrm{~m}$, também se nota formas geométricas irregulares, com pinceladas em preto, azul escuro, verde, branco, amarelo e alaranjado. Ao redor das formas geométricas há grandes manchas em azul claro que os envolve. (BEZ; SANTOS, 2010, p. 366).

Figura 1- Pecado Capital - Ira, 1949. Óleo sobre tela, 0,70m x 0,70m.

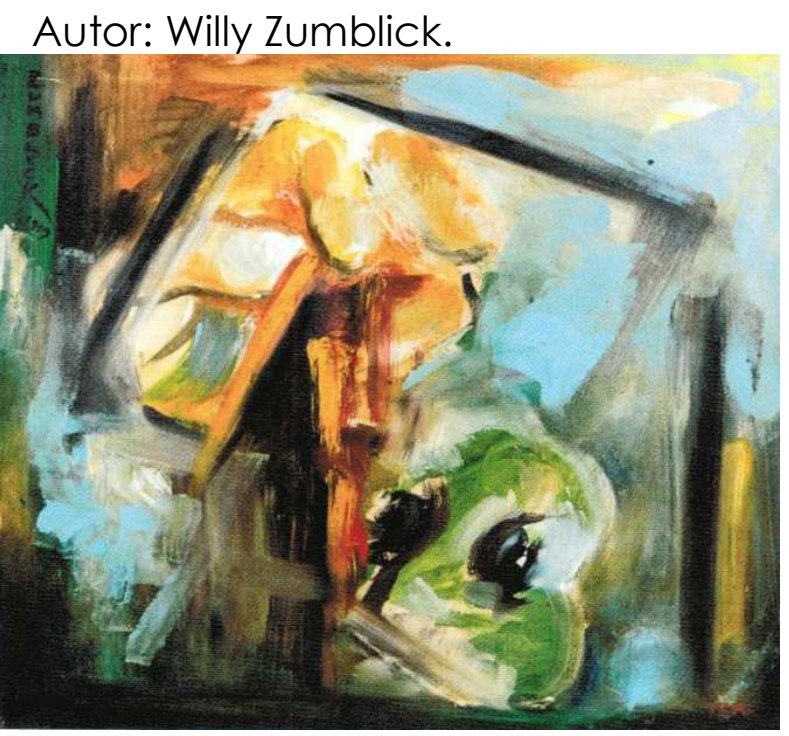

Fonte: Bez e Santos (2010, p. 366).

A referência a essas obras se deve ao fato delas terem sido produzidas um ano após a formação do Grupo Sul em Florianópolis, e no mesmo ano em que foi inaugurado o Museu de Arte Moderna de Santa Catarina, levando em consideração que a produção destas telas não pode ser compreendida como evento isolado e distanciado dos 
ROSA, Murilo de Sousa. Incursões fantasiosas: o modernismo primitivista na arte de Willy Zumblick, 1973. Domínios da Imagem, Londrina, v. 10, n. 19, p. 189-211, jul./dez. 2016.

ISSN 2237-9126

acontecimentos que envolvem as artes catarinenses. Os jornais de Tubarão divulgavam em artigos e notas eventos que ocorriam na capital catarinense, incluindo exposições de artes, bem como as mostras de Willy pelo Estado e pelo país. É provável que o artista tenha tomado conhecimento sobre as ações dos modernistas no ano de 1948,2 já que Willy era leitor do periódico A Imprensa. ${ }^{3}$ O ano de 1948 foi uma data significativa por marcar também 0 sucesso de uma exposição de Willy em Florianópolis, e comemorada nas páginas de revista tubaronense Cidade Azul, e que, além de reproduzir os artigos que foram editados no Jornal $O$ Estado, publicou um poema dedicado a Zumblick de autoria do modernista do Grupo Sul, Ody Fraga, intitulado Quando a porta ranger. ${ }^{4}$ Desse modo, é provável que a repercussão da exposição de Zumblick não tenha passado despercebida pelos modernistas do Grupo Sul, já que a poesia dedicada a Willy por um de seus membros permite compreender que ambos, tanto 0 artista tubaronense quanto o Grupo, conheciam as produções alheias.

Essas circunstâncias nos permitem observar que Willy tinha interesse sobre arte moderna desde o fim da década de 1940, e assim como o Grupo Sul, acompanhou as inovações nas artes, e incursionou pelo modernismo, pois defendeu que "o artista tem o direito de fazer suas aventuras, fugindo de seus padrões normais". (ZUMBLICK, 1998 p. 110).

\footnotetext{
2 Revista "Sul". A Imprensa, Tubarão, 20 mar. 1948. Ano XV., n. 634, p. 1.

${ }^{3}$ Ao realizar uma pesquisa no acervo pessoal de Willy Zumblick, concedida por sua filha Maria Elisa Zumblick, foi possível perceber que o pintor guardava recorte de jornais publicados não só em sua terra natal, como também de outras cidades do Estado e do país.

${ }^{4}$ S. Ody F. e. Quando a porta ranger. Revista Cidade Azul, Tubarão, ano 1, junho de 1948, n. 2.
} 
ROSA, Murilo de Sousa. Incursões fantasiosas: o modernismo primitivista na arte de Willy Zumblick, 1973. Domínios da Imagem, Londrina, v. 10, n. 19, p. 189-211, jul./dez. 2016.

ISSN 2237-9126

\section{Primitivista E Renovador}

No ano de 1973 Zumblick pintou para um hotel da cidade de Laguna, da costa catarinense, uma coleção de pouco mais de cem quadros, entre os quais estão motivos folclóricos e de veraneio. (ZUMBLICK, 1998, p. 61). No texto intitulado Pós-impressionismo primitivista, o crítico de arte Antônio Minguetti identificou as características visuais deste conjunto, todas com 0,40m x 0,30m, e ao descrevê-las falou de suas formas com contornos visíveis, a aplicação de cores puras, linhas curvas e a falta de sombras.

Figura 2 - Santo Antônio, década de 1960. Escultura em aço e concreto, $4,20 \mathrm{~m} \times 2,50 \mathrm{~m}$. Autor: Willy Zumblick.

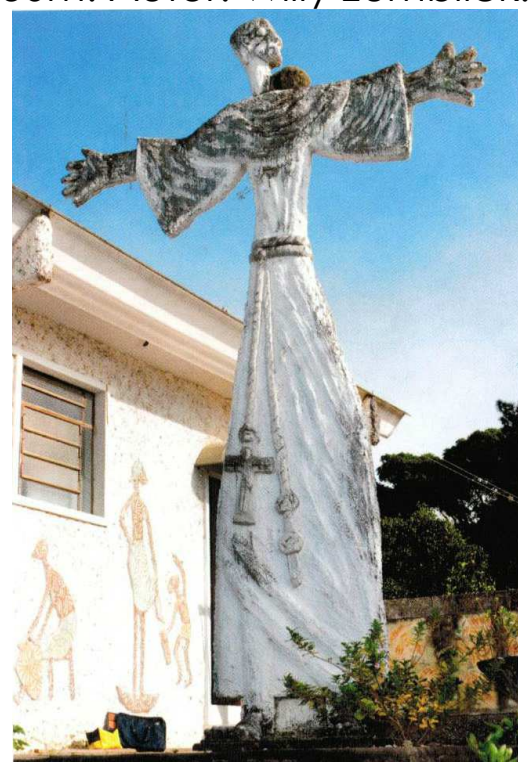

Fonte: Bez E Santos (2010, p.398).

Apesar de Minguetti dedicar um capítulo do livro Zumblick para sempre para tratar desta coleção, outras experiências de Willy com a estética primitivista passaram despercebidas. Ao analisar as imagens disponíveis na biografia, é possível perceber que o artista já havia desenvolvido outros trabalhos com essa linha estética. No seu atelier, intitulado Rancho do Vô, há duas grandes esculturas de concreto e 
ROSA, Murilo de Sousa. Incursões fantasiosas: o modernismo primitivista na arte de Willy Zumblick, 1973. Domínios da Imagem, Londrina, v. 10, n. 19, p. 189-211, jul./dez. 2016.

ISSN 2237-9126

aço, calhadas de branco, que datam da década de 1960, uma com 4,20m de altura e 2,50m de largura, e outra com 4,10m e 1,60 de medidas. A primeira, que representa Santo Antônio em pé, de perfil e de braços abertos, possui linhas irregulares, corpo alongado, quadril largo, cintura fina, pescoço comprido e estreito, e braços e mãos grossas. A segunda escultura é uma representação do próprio artista de corpo inteiro, calhada de branco, usando chapéu e segurando pincéis e paleta de pintura. A peça também possui linhas irregulares, corpo alongado, cintura fina e braços grossos. Atrás dessas esculturas, foram feitos altos-relevos em uma parede com as mesmas características, representando uma brincadeira de boi-de-mamão. Os personagens possuem membros finos, alongados e curvos, com contornos visíveis e com linhas circulares que preenchem seus corpos, além de apresentar algumas formas geométricas nos instrumentos musicais. Na composição predominam apenas três cores: marrom, verde e alaranjado. (BEZ; ROCHA, 2010).

Com base nas imagens impressas em suas biografias, percebe-se que foi durante as décadas de 1960 e 1970 que o artista tubaronense mais se dedicou a produção de obras primitivistas. No ano de 1962, Willy produziu uma aquarela sobre papel, abordando boi-de-mamão e recorrendo à mesma estética. Seu trabalho primitivista ressurgiu em 68 na parede do Edifício Presidente em Florianópolis, num painel de $9,00 \mathrm{~m}$ x 2,30m, intitulado Costumes da llha. No ano de 1970, Willy pintou um conjunto intitulado Zodíaco, e nesta sequência apenas duas foram confeccionadas com aspectos do estilo em discussão: Virgem e Aquário. Do mesmo modo, produziu dois anos depois A última Ceia, uma pintura feita com gesso e óleo sobre Eucatex, com 1,40m x 0,80m.

$\mathrm{Na}$ capital do Estado, as ações do Grupo Sul chamavam a atenção do "mundo artístico" catarinense. Os modernos da llha 
ROSA, Murilo de Sousa. Incursões fantasiosas: o modernismo primitivista na arte de Willy Zumblick, 1973. Domínios da Imagem, Londrina, v. 10, n. 19, p. 189-211, jul./dez. 2016.

ISSN 2237-9126

conseguiram trazer para Florianópolis alguns nomes de destaque das artes, entre eles o escultor Bruno Giorgi, que em sua visita conversou com os jovens sobre a liberdade criadora, impressionismo, fauvismo, cubismo, surrealismo, dadaísmo e abstracionismo. (SABINO, 1981, p. 6970). Algum tempo depois, em Brasília, Bruno Giorgi assinou um dos símbolos mais conhecidos da construção da nova capital do país: os candangos. A peça de nove metros de altura, feita em bronze, foi concluída em 1959 e corresponde a sua fase figurativa. A peça foi aprovada por Oscar Niemeyer para ornamentar a Praça dos Três Poderes e homenagear os que ergueram a cidade. Basicamente, os aspectos formais apresentam corpos estilizados, finos, verticais, quadris salientes, cinturas estreitas, pescoços alongados, braços abertos e sem rosto.

Essas atribuições são semelhantes as das esculturas de Willy, mas não há até então registros de que ele teve a oportunidade de encontrar o autor dos candangos em Florianópolis quando este visitou o Grupo Sul. No entanto, as repercussões sobre a construção de Brasília na mídia da época reforçam a visibilidade das obras de Bruno Giorgi, e as semelhanças configuram como mais uma "aventura" de Willy nas artes modernas. 
ROSA, Murilo de Sousa. Incursões fantasiosas: o modernismo primitivista na arte de Willy Zumblick, 1973. Domínios da Imagem, Londrina, v. 10, n. 19, p. 189-211, jul./dez. 2016.

ISSN 2237-9126

Figura 3- A caminho das ondas, 1973. Gesso e óleo sobre tela, 0,30m x 0,40m. Autor: Willy Zumblick.

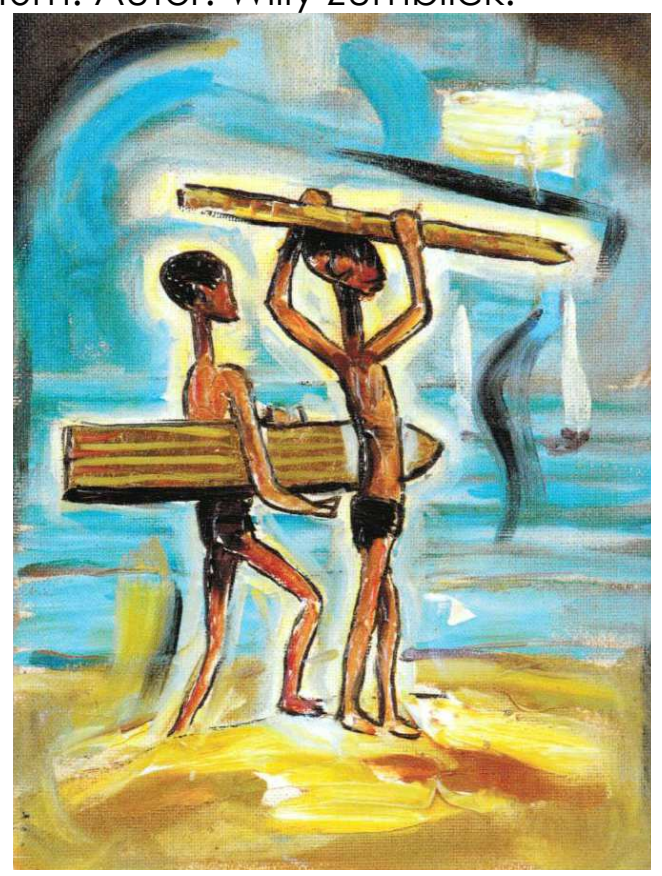

Fonte: Bez e Santos (2010, p. 340).

Como vimos acima, no decorrer dos anos, Willy Zumblick criou alguns trabalhos modernistas, até realizar o conjunto de obras primitivistas de 1973, e apesar da diversidade temática abordada, é possível perceber alguns aspectos em comum. No conjunto há quadros que tratam de ambientes e costumes populares do litoral e do interior do Estado, como pessoas recolhendo água do poço, brincadeiras de boi-de-mamão, pescadores com suas redes, brigas de galo, danças típicas, festas religiosas, carros de boi, domadores de cavalos, pescadores, rendeiras, lavadeiras e casas simples, além de representar mineiros, violeiros, sanfoneiros, bailarinas, espantalhos, malabaristas, seresteiros, engraxates e pedintes. Nas obras que tratam de temas marinhos há veranistas em trajes de banho, guarda-sóis, bóias, barcos, pranchas e surfistas sobre as ondas. Em muitas dessas pinturas predominam o amarelo, alaranjado, ocre e marrom, e muitos deles estão envolvidos por largas manchas de tons terrosos, azul, verde ou 
ROSA, Murilo de Sousa. Incursões fantasiosas: o modernismo primitivista na arte de Willy Zumblick, 1973. Domínios da Imagem, Londrina, v. 10, n. 19, p. 189-211, jul./dez. 2016.

ISSN 2237-9126

preto. Com relação ao aspecto formal as figuras apresentam membros finos e alongados, com contornos pretos, geralmente largos e tortos, e os detalhes das faces, pés e mãos não são acrescentados. Outros rostos são reconhecíveis devido às pinceladas de preto que representam bocas, olhos e narizes. Nas telas onde as faces são um pouco mais detalhadas, há círculos brancos com pequenos detalhes negros que representam os olhos, narinas largas e bocas são linhas curvas negras que dividem formas ovais na horizontal configurando grossos lábios vermelhos. No geral, as obras foram realizadas com gesso e tinta óleo sobre madeira Eucatex.

Pelo fato da coleção ter mais de cem quadros, essa circunstância impossibilita um estudo minucioso sobre todas as telas nesse artigo. Porém, escolhi a tela Bandeira do Divino Fonte: (BEZ; SANTOS, 2010, p. 340) para uma análise mais detida. O motivo da escolha tem uma justificativa: a Festa do Divino Espírito Santo é um dos temas prediletos de Willy, e consequentemente um dos mais divulgado através da mídia. $\mathrm{Na}$ imagem há dois personagens, integrantes da cantoria da Festa do Divino Espírito Santo, evento religioso típico do litoral catarinense. $O$

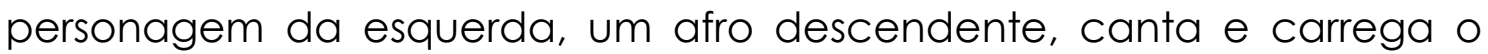
tambor que marca o ritmo da música. Mesmo com os pés fixos no chão, seu corpo pende flexivelmente para esquerda. Esta figura apresenta contornos bem nítidos, porém irregulares. Ela é esguia, com membros finos e curvos. Não houve a aplicação de detalhes nos pés, mãos e orelhas, e nem foco de luz na cena ou a sensação de volume. Seu rosto possui poucos traços em preto que representam as sobrancelhas, olhos e nariz. Já a sua boca, escancarada, é uma grande mancha preta sem detalhes, e cercada por largas pinceladas de vermelho. Com relação às pinceladas elas mais parecem manchas, e as cores usadas são poucas: marrom, ocre, azul marinho cinza. 
ROSA, Murilo de Sousa. Incursões fantasiosas: o modernismo primitivista na arte de Willy Zumblick, 1973. Domínios da Imagem, Londrina, v. 10, n. 19, p. 189-211, jul./dez. 2016.

ISSN 2237-9126

Figura 4- Bandeira do Divino, 1973. Óleo sobre Eucatex, 0,30m x 0,40m. Autor: Willy Zumblick.

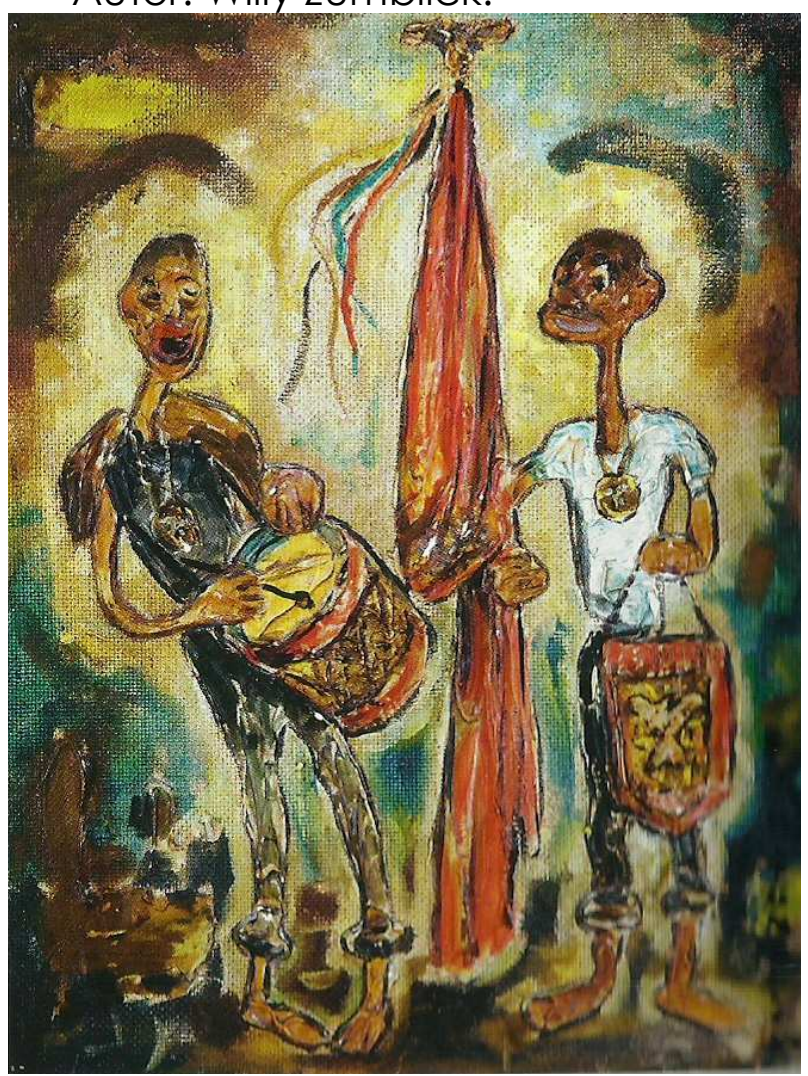

Fonte: Bez e Santos (2010, p. 340).

O personagem da direita, também afro descendente, carrega 0 estandarte e a bandeira da festividade. Os aspectos referentes aos contornos, traços, linha, detalhes, volume, proporções e cor são idênticos à figura da esquerda. No entanto, sua veste é uma camiseta branca e uma calça que mistura azul marinho e cinza escuro. Com relação ao rosto o que se pode ver com nitidez é boca. Em comum, as figuras estão com os pés descalços, revelando ser gente humilde, e com as pontas das calças dobradas, como fazem os pescadores para entrar no mar. Ao redor deles Zumblick aplicou contornos claros e largos, com tons de amarelo, azul escuro e marrom. Quanto ao chão o que se vê são borrões de marrom, cinza escuro e preto que logo se 
ROSA, Murilo de Sousa. Incursões fantasiosas: o modernismo primitivista na arte de Willy Zumblick, 1973. Domínios da Imagem, Londrina, v. 10, n. 19, p. 189-211, jul./dez. 2016.

ISSN 2237-9126

misturam as manchas que estão atrás dos personagens, pois não há uma linha que divide os dois espaços. Enfim, o que se vê é a representação de uma cena estilizada, e não uma representação realista.

A pesquisadora Mônica Eustáquio Fonseca argumenta que o primitivismo foi à primeira forma de reconhecimento das culturas não europeias, opondo-se a cultura ocidental urbana, e os primeiros artistas a se interessarem por essa forma de pintar foram Gauguin, Picasso e Matisse. Suas telas, por terem sido trabalhadas com técnicas e expressões simples, diretas, aplicação de áreas planas de cor e distorções, aparentam ser rudes e inacabadas, mas o interesse em comum era produzir uma arte próxima das artes primitivas africanas e asiáticas. Já no Brasil Lasar Segall e Anita Malfatti também optam por cores não naturais, volumes maciços e sem detalhes, e segundo Fonseca (2004, p. 111-112) "O primitivismo foi à porta pelo qual os modernistas penetraram no Brasil", Para a autora, Tarsila do Amaral, com linhas claras e cores chapadas, foi a primeira artista a fazer uma transcrição do interior caipira do país para as telas.

Ao conferir essas características se percebe que Zumblick (1998, p. 109) conhecia bem as orientações da pintura moderna, e não por acaso que admitiu sua admiração por artistas modernistas, "como Anita Malfatti, Portinari, Milton da Costa, Inimá de Paula, Pancetti". Mesmo que Zumblick não tenha citado Tarsila do Amaral como um dos artistas que the chamavam a atenção, é possivel perceber semelhanças entre os personagens de algumas de suas obras. Um exemplo notável está nas bocas de algumas figuras primitivistas de Willy e a personagem da tela A Negra de Tarsila, de 1923. Outra semelhança entre Tarsila e Willy é que ambos representaram a Bandeira do Divino, e na obra dela, desenvolvida entre 1939 a 1968, seu personagem está trajado de forma 
ROSA, Murilo de Sousa. Incursões fantasiosas: o modernismo primitivista na arte de Willy Zumblick, 1973. Domínios da Imagem, Londrina, v. 10, n. 19, p. 189-211, jul./dez. 2016.

ISSN 2237-9126

muito parecida com a figura à direita do quadro Bandeira do Divino de Willy, ou seja, camisa branca e calça azul com as bainhas dobradas. (SITE OFICIAL DE TRASILA, 2015). Coincidência ou não, no mesmo ano em que Willy desenvolveu sua coleção primitivista, na qual se inclui sua Bandeira do Divino, Tarsila havia falecido em 17 de janeiro de 1973, aos 86 anos de idade.

O pesquisador Arley Andriolo identificou outro atributo do primitivismo: a alteridade. Andriolo (2006) faz lembrar que o primitivismo não é uma escola e nem está relacionado a um período da história da arte, e sobre o termo foram construídos sentidos tanto pejorativos quanto positivos. Para a ciência darwinista, o primitivismo está relacionado à cultura de povos considerados menos evoluídos. Mas para os artistas como Gauguin, o caminho é inverso, e no contato com o outro, distante da cultura dos grandes centros urbanos, o primitivismo representa pureza, e a pintura converte o estereótipo em uma ideia positiva. Ao mesmo tempo, esta arte é subversiva, pois suas representações trazem camponeses, ciganos, loucos, prostitutas, artistas de circo e pobres. Ou seja, dá visibilidade aos marginalizados no interior da própria cultura, aos que não são favorecidos pelo progresso material e econômico, ou apresenta ainda os que não são percebidos devido à distância, como fizeram Matisse e Picasso quando passaram a produzir, recorrendo às estéticas africanas.

Assim como esses exemplos citados acima, Zumblick também incluiu na sua arte primitivista os marginalizados do seu Estado. Willy colocou, ao lado de banhistas e surfistas, pescadores, rendeiras, lavadeiras, mineiros, engraxates e pedintes, estando o pintor consciente do papel social do conteúdo crítico do primitivismo, e revela seu olhar atento, voltado para dentro de sua cultura, para a gente simples do cotidiano. 
ROSA, Murilo de Sousa. Incursões fantasiosas: o modernismo primitivista na arte de Willy Zumblick, 1973. Domínios da Imagem, Londrina, v. 10, n. 19, p. 189-211, jul./dez. 2016.

ISSN 2237-9126

A escolha de Zumblick pela estética primitivista para pintar sua coleção de 1973 está ligado também ao panorama artístico catarinense da época. Neste ano Willy assumiu o cargo de presidente da Comissão Municipal de Turismo de Tubarão, e um dos eventos realizados sobre sua responsabilidade foi o Festival Hoje (1973, p. 8), que ocorreu em novembro daquele ano, e entre os eventos programados estava a Exposição de Artes Plásticas. Com relação a este mostra o Nosso Jornal destacou que "participarão artistas catarinenses, principalmente renovações". O Nosso Jornal voltou a tratar do Festival, destacando sua inauguração, e

Na ocasião, foi aberta a exposição de Artes, tendo como expositores: Willy Zumblick, Iolanda Zappelini, Lorena Genovez, Maxim, Vera Sabino, Rodrigo de Haro, Marília Sá, Odil Campos, Albertina Prates, Olegário Marniére, Portugues, Mey(e)r Filho, e Ma . Estér e outros. (TRI em cima, 1973, p. 8).

Entre os que participaram desta coletiva, chama atenção a presença de Meyer Filho e Rodrigo de Haro, pois ambos, além de reconhecidos artistas catarinenses, pareciam atender as intenções de apresentar "renovações" no festival, como desejava Willy. Ernesto Meyer Filho, ex-ilustrador do Grupo Sul, foi um dos fundadores do GAPF, que também defendeu a produção artística modernista. Jaqueline Wilde Lins argumenta que Meyer fez parte de uma geração de artistas da capital que trabalhou com o mito-mágico fantástico, e produziam sua arte de acordo com os mitos contados no interior da llha de Santa Catarina. Meyer recriava o imaginário local através de uma narrativa onírica, dando atenção ao folclore, entre eles o boi-de-mamão e elementos bruxólicos com feições humanas distorcidas, além de representar personagens populares e paisagens locais. Um dos temas 
ROSA, Murilo de Sousa. Incursões fantasiosas: o modernismo primitivista na arte de Willy Zumblick, 1973. Domínios da Imagem, Londrina, v. 10, n. 19, p. 189-211, jul./dez. 2016.

ISSN 2237-9126

mais desenvolvidos por Meyer Filho foram seus galos, e com o passar do tempo se tornavam mais estilizados, irreais e abstratos, com formas primitivas, ao ponto de dar a um deles o nome de "Galo Picasso". Lins (2010) destacou também que o próprio Meyer Filho não classificava sua arte em um único estilo, mas coexistiam primitivismo, surrealismo e real fantástico. Com o GAPF, o interesse por temas mito-mágicos, ou seja, imaginários ou fantásticos, junto com temas locais, se cristalizam, e artistas mais novos também passam a focá-los, entre eles Rodrigo de Haro, outro integrante do GAPF.

A exposição coletiva conduz a outras reflexões sobre produção primitivista de Willy do ano 1973. O convite feito aos "renovadores" reafirma o quanto Willy tinha interesse pelo modernismo, e através de uma coletiva com essa perspectiva também se mostraria como um dos "renovadores", e não um "retrógado". Como observou Joly (2007, p. 50) "Qualquer que seja o mundo marginal em que o artista se movimenta (da corte do príncipe à boemia), este não se encontra isolado: pertence à grande família dos gênios". E desse modo, acompanhando as tendências da arte, Willy optou pelo primitivismo como um modo de representar a diversidade social, criando imagens sobre o veraneio, mas deu também a gente comum representações em sua arte.

\section{Considerações Finais}

No ano de 2013, no qual se comemorou os cem anos de nascimento de Willy Zumblick, a e mídia outras instituições catarinenses homenagearam o pintor através de suas publicações. Parte do que foi apresentado em artigos são redundantes, retomando o que já havia sido apresentado em suas biografias, e não houve um interesse em apresentar por quais motivos Willy pintava da forma que pintava. A 
ROSA, Murilo de Sousa. Incursões fantasiosas: o modernismo primitivista na arte de Willy Zumblick, 1973. Domínios da Imagem, Londrina, v. 10, n. 19, p. 189-211, jul./dez. 2016.

ISSN 2237-9126

classificação e a descrição dos estilos de sua pintura foram tratadas no livro Zumblick para sempre, porém, sem contextualizá-los.

Ao observar as imagens em suas biografias percebe-se que Willy investiu na diversidade de estilos. O pintor argumentou que muitos artistas, inclusive ele, para não se acomodar, acabam experimentando outros jeitos de pintar, e nessas "aventuras", passou a trabalhar com o modernismo, fazendo suas "incursões fantasiosas".

Ao visitar a ENBA, O artista fubaronense encontrou um lugar dividido entre o academicismo e o modernismo, o que ampliou sua experiência com a pintura.

O interesse de Zumblick pelo modernismo pode ser percebido através das esculturas construídas em seu atelier, que se assemelham aos Candangos, de Bruno Giorgi, assim como seus quadros primitivistas de 1973 tinham aspectos que podem ser identificados nos trabalhos de Tarsila do Amaral.

A atividade dos modernistas de Florianópolis era algo que Willy também acompanhou, mantendo contato com ex-integrantes do GAPF, aos quais chamou de "renovadores", e reafirmando seu interesse pelo modernismo.

Há outra semelhança entre a arte Zumblick de 1973 e a dos artistas citados acima. Além de optarem pela estética primitivista, estes focaram como tema o cotidiano da gente comum, excluídos do progresso material e os marginalizados. Desta forma, Willy demonstrou conhecer o papel subversivo que essa arte aparentemente rude desempenhava ao dar visibilidade aos populares locais com as suas dificuldades de sobrevivência. Além disso, o interesse de Zumblick pelo modernismo não foi um caso eventual, mas algo experimentado e ampliado durante os anos de sua carreira. 
ROSA, Murilo de Sousa. Incursões fantasiosas: o modernismo primitivista na arte de Willy Zumblick, 1973. Domínios da Imagem, Londrina, v. 10, n. 19, p. 189-211, jul./dez. 2016.

ISSN 2237-9126

\section{Referências}

ANDRADE FILHO, João Evangelista. 50 anos do GAPF. Florianópolis: [s.n.], 2001.

ANDRIOLO, Arley. A questão da alteridade no "primitivismo artístico". In: ENCONTRO DE HISTÓRIA DA ARTE, 2., 2006, Campinas. Atas... Campinas: IFCH/UNICAMP, 2006. p. 14-20.

BEZ, Volnei Martins; ROCHA, Valmiré. A arte de Zumblick. Tubarão, 2005.

BEZ, Volnei Martins; ROCHA, Carlos. Zumblick para sempre - catálogo de obras. Florianópolis: Secco, 2010.

COUTO, Maria de Fátima Morethy. Modernos ou vanguardistas: a construção do moderno na arte brasileira na primeira metade do século XX. 2005. Disponível em:

<http://www.iar.unicamp.br/dap/vanguarda/artigos_pdf/fatima_moreth y.pdf>. Acesso em: 15 jan. 2014.

CHEREM, Rosângela; MAKOWIECKY, Sandra. Academicismo e modernismo em Santa Catarina. Florianópolis: Ed. da UDESC, 2010, 1CDROM.

FESTIVAL: Hoje em Tubarão. Nosso Jornal, Tubarão, 29 set. 1973. n. 494, p 8.

TRI em cima. Festival Hoje. Nosso Jornal, Tubarão, 17 nov. 1973. n. 501, p.8.

FONSECA, Mônica Eustáquio. "Os loucos anos 20". O primitivismo ou a inscrição da "Terra Brasilis" no concerto internacional. Cadernos de Arquitetura e Urbanismo, Belo horizonte, v. 11, n.12 p.99-116, dez. 2004.

JOLY, Martine. Introdução à Análise da Imagem. Lisboa: Ed. 70, 2007.

JUNKES, Lauro. Anibal Nunes Pires e o Grupo Sul. Florianópolis: Ed. da UFSC/Lunardelli, 1982.

LINS, Jaqueline Wilde. O Universo plástico de Meyer Filho. In: SEMINÁRIO DE PESQUISA ACADEMICISMO E MODERNISMO EM SANTA CATARINA, 2010, Florianópolis. Apresentação dos artigos... Florianópolis: UDESC, 2010. CD-ROM. p, 294-312. 
ROSA, Murilo de Sousa. Incursões fantasiosas: o modernismo primitivista na arte de Willy Zumblick, 1973. Domínios da Imagem, Londrina, v. 10, n. 19, p. 189-211, jul./dez. 2016.

ISSN 2237-9126

LUZ, Angela Ancora da. A Escola Nacional de Belas Artes: porões e salas ou modernidade e tradição. In: COLÓQUIO DE HISTÓRIA DA ARTE -

CBHA, 22., 2002, Porto Alegre. Disponível em:

<http://www.cbha.art.br/coloquios/2002/ textos/textol 1.pdf>. Acesso em: 10 set. 2015.

MINGUETTI, Antônio A. Desvalendo a arte de Zumblick. In: BEZ, Volnei Martins; SANTOS, Valmiré Rocha dos. Zumblick para sempre - catálogo de obras. Florianópolis: Secco, 2010. p. 27-30.

NUNES, Lélia Pereira da Silva. Zumblick - uma história de vida e arte. Brasília: Senado Federal, 1993.

NUNES, Lélia Pereira da Silva; NUNES, Rute Viera. Entre penas e pincéis: manuscritos inéditos do artistas plástico - Willy Zumblick. Tubarão: Ed. Universitária da UNUSUL, 1998.

SABINO, Lina Leal. Grupo Sul: o modernismo em Santa Catarina. Florianópolis: Fundação Catarinense de Cultura, 1981.

SITE OFICIAL TARSILA DO AMARAL. Obras. Disponível em: $<$ http://tarsiladoamaral.com.br/?post_type=work\&posts=all/>. Acesso em: 13 maio 2015.

ZUMBLICK, Willy. Reflexões. In: NUNES, Lélia Pereira da Silva. NUNES, Rute Vieira. Entre penas e pincéis - manuscritos inéditos do artista plástico Willy Zumblick. Tubarão: Ed Universitária da UNISUL, 1998. p. 110. 